\title{
(2-Fluoroallyl)pyridinium tetrafluoroborates: novel fluorinated electrophiles for Pd-catalyzed allylic substitution
}

\author{
Angelina Yu. Bobrova ${ }^{a, b}$, Maxim A. Novikova*, and Yury V. Tomilov \\ a. N.D. Zelinsky Institute of Organic Chemistry, Russian Academy of Sciences, 47 Leninsky prosp., 119991 Moscow, Russian Federat ion. \\ b. Higher Chemical College of the Russian Academy of Sciences, D. I. Mendeleev University of Chemical Technology of Russia, 9 \\ Miusskaya pl., 125047 Moscow, Russian Federation \\ Fax: +7499 13563 90; e-mail: manovikov@ioc.ac.ru
}

An efficient two-step approach to 2-fluoroallyl amines was developed that involves the synthesis of (2-fluoroallyl)pyridinium tetrafluoroborates from readily available gembromofluorocyclopropanes and the application of the former as novel and stable 2-fluoroallyl electrophiles for Pd-catalyzed allylic substitution.

Fluorinated bioisosteres have found a broad application in the modern drug design. ${ }^{1}$ In particular, a fluoroalkene moiety can efficiently mimic an amide bond due to a similarity in the electronic and steric parameters, thus increasing the hydrolytic stability, lipophilicity, and permeability through membranes. ${ }^{2}$ As a result, by using such bioisosteric replacement, one could substantially improve the efficiency of biologically active compounds known to date (Scheme 1).

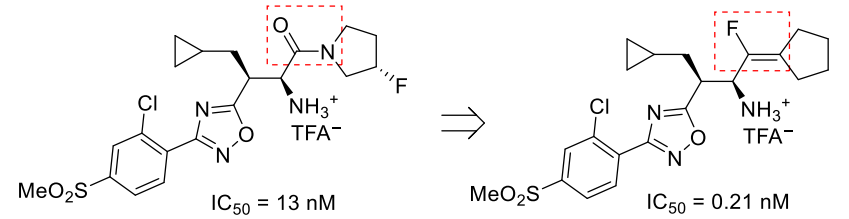

Scheme 1. An example of bioisosteric replacement of an amide moiety by a fluoroalkene that resulted in enhanced DPP-IV inhibition (potential treatment of type 2 diabetes) ${ }^{3}$

Of the other approaches ${ }^{4}$, ring opening in fluorinated cyclopropanes has been known for a long time as a valuable method for the preparation of fluoroalkenes and 2-fluoroallyl derivatives (Scheme 2, A). ${ }^{5}$ This fluorocyclopropane-based strategy potentially allows one to obtain complex fluorinated molecules from simple alkenes via the formal "insertion" of a CF moiety into a $\mathrm{C}=\mathrm{C}$ double bond. ${ }^{6}$ However, its real synthetic applications were limited for a long time by the scarce scope of substrates. ${ }^{7}$ The most probable reason for that situation is the inability to control the regio- and stereochemical outcome of the non-selective nucleophile addition to 2-fluoroallyl cationic structures that are the key intermediates in these processes (Scheme 2, A).

In the past decade, the interest in the ring-opening transformations of fluorinated cyclopropanes grew again. However, despite the wide range of neighboring group assisted rearrangements developed, ${ }^{8}$ examples of ring-opening of nonactivated fluorocyclopropanes are rare. ${ }^{9}$ Of these, palladiumcatalyzed 2-fluoroallylation of various nucleophiles with gemdifluorocyclopropanes using Buchwald's biarylphosphines as the ligands were reported (Scheme 2, B). ${ }^{10}$ Processes of this type can be applied to a wide range of nucleophiles and represent a new mode of activation of a fluorinated cyclopropane ring. However, the most significant limitation is that only monosubstituted gem-difluorocyclopropanes can react under these conditions. Moreover, diaryl-substituted gem-difluorocyclopropyl stannanes that were used for the 2fluoroallylation of alcohols and some amides should be mentioned (Scheme 2, C). ${ }^{11}$ The reaction occurs via generation of fluorocyclopropenes that undergo a rearrangement to fluoroalkenylcarbenes, followed by insertion into an acidic $\mathrm{O}-\mathrm{H}$ or N-H bond of nucleophiles.

Our team recently disclosed the CuX-catalyzed isomerization ${ }^{12 a}$ and nucleophilic substitution ${ }^{12 b, c}$ of gemchlorofluoro- and gem-bromofluorocyclopropanes to give various 2-fluoroallylic derivatives, and particularly 2-fluoroallyl amines. ${ }^{12 c}$ (Scheme 2, D). These rearrangements are not so sensitive to the number of substituents at the cyclopropane ring as Pd-catalyzed ring-opening of gem-difluorocyclopropanes mentioned above. However, these CuX-catalyzed processes have all the issues known previously, i.e., low $Z / E$-selectivity in many cases of the formation of 2-fluoroallyl derivatives, limited scope of nucleophiles, and complications caused by side dehydrohalogenation or polymerization. 
A. General strategy. Transformation of alkenes to 2-fluoroallyl compounds with chain-elongation by one carbon atom

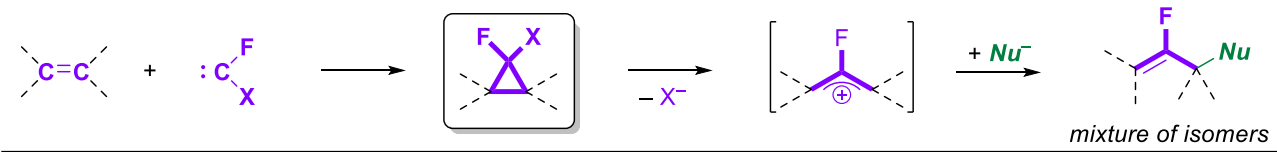

B. Pd-catalyzed ring-opening of gem-difluorocyclopropanes

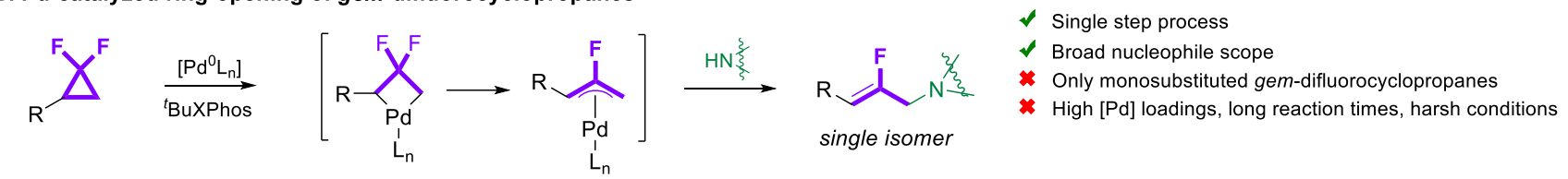

C. Ring-opening of gem-difluorocyclopropyl stannanes

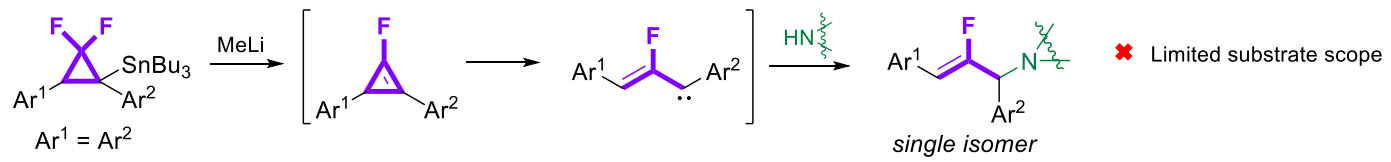

D. Our CuX-catalyzed ring-opening of gem-chlorofluoro- and gem-bromofluorocyclopropanes

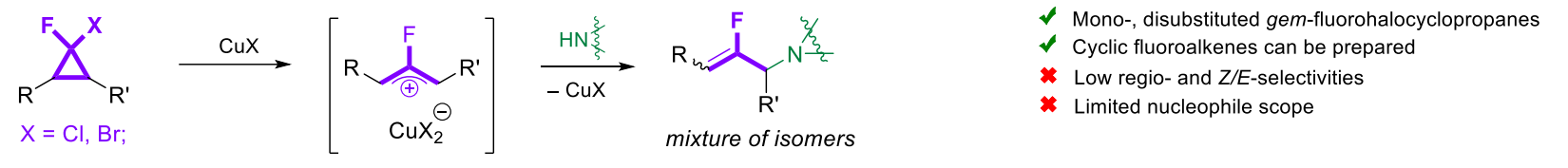

E. Current work: Synthesis of (2-fluoroallyl)pyridium salts by CuBr-catalyzed ring-opening of gem-bromofluorocyclopropanes and their use in Pd-catalyzed allylic amination

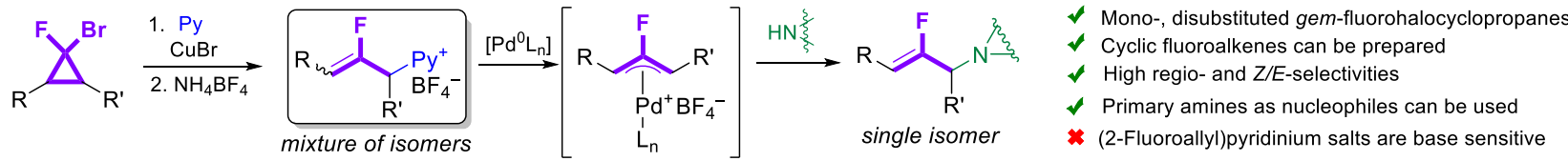

Scheme 2. Synthesis of 2-fluoroallyl amines by ring-opening rearrangements of fluorinated cyclopropanes

In this work, we report an efficient two-step sequence for the conversion of gem-bromofluorocyclopropanes ${ }^{13}$ into 2fluoroallyl amines via intermediate formation of (2fluoroallyl)pyridinium salts as novel and stable 2-fluoroallyl electrophiles for Pd-catalyzed allylic substitution (Scheme 2, E).

Initially, CuX-catalyzed ring-opening of gembromofluorocyclopropanes was carried in the presence of pyridine or using pyridine as the solvent to give (2fluoroallyl)pyridinium salts as the main products (Scheme 3 ). The reaction required occurred at $100^{\circ} \mathrm{C}$ and took from $5 \mathrm{~h}$ to several days of heating, depending on the substituents.

Though elevated temperatures and long reaction times are required, this process can be used to obtain a wide range of aryl(2a, 2b) and alkyl-substituted (2c, 2f, 2g, 2j) 2-fluoroallyl pyridinium salts, including those with ester substituents (2d, 2f), a malonate moiety (2i), or a second fluorine atom (2k) in the 2fluoroallyl moiety. Moreover, the 2-fluoroallyl moiety can be incorporated into the cyclic structure (2h), which is hardly accessible by other methods. ${ }^{14}$ In many cases, pyridinium salts are formed as mixtures of $Z / E$ - or even linear/branched isomers. Although these pyridinium salts can be isolated by column chromatography on $\mathrm{NaBr}$-saturated silica gel or sometimes by simple filtration (see ESI for details), the easiest way is to convert them to tetrafluoroborate salts and extract the latter with $\mathrm{CH}_{2} \mathrm{Cl}_{2}$.

Preliminary attempts to utilize salt $\mathbf{2 a}$ in nucleophilic substitution or as a source of a 1,3-dipole revealed that $\mathbf{2 a}$ was sensitive to bases such as primary, secondary, or tertiary amines, $\mathrm{MOH}$ or $\mathrm{M}_{2} \mathrm{CO}_{3}$ ( $\mathrm{M}=$ alkali metal), or LDA to give complex mixtures of non-fluorinated products.

Surprisingly, pyridinium salts were found to be prone to the fast oxidative addition of $\mathrm{Pd}^{0}$. In fact, when $\mathrm{Pd}_{2} \mathrm{dba}_{3} / \mathrm{PPh}_{3}$ or $\mathrm{Pd}_{2} \mathrm{dba}_{3} / \mathrm{SPhos}$ solutions in THF are added to excess pyridinium salts $\mathbf{2 a}$ or $\mathbf{2} \mathbf{h}$, the deep red or brown color of $\mathbf{P d}^{0}$-complexes disappeared in minutes at r.t. to give yellow mixtures as it is typical if allyl palladium(II) complexes are formed. ${ }^{15}$ 


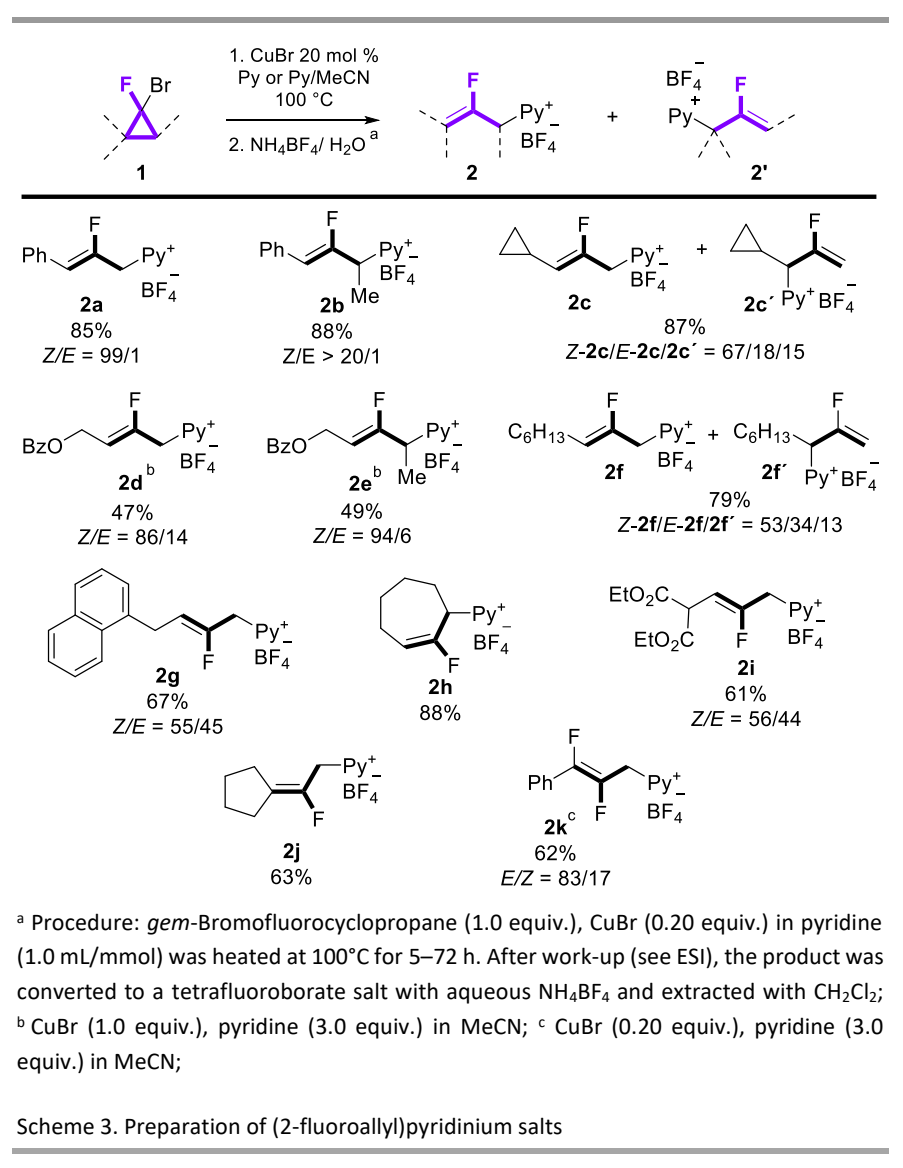

Encouraged by these results, we decided to optimize the Pdcatalyzed amination of salt $\mathbf{2 h}$ with model $\mathrm{N}$-cyclohexyl-4methoxybenzylamine 3a (Table 1). It was found that XantPhos was superior to $\mathrm{PPh}_{3}$ (Entry 1 vs. 2), while $\mathrm{Na}_{3} \mathrm{PO}_{3}$ (Entry 3) was much more efficient as the base than other alkali metal phosphates $\left(\mathrm{K}_{3} \mathrm{PO}_{4}\right.$ - Entry $2 ; \mathrm{Li}_{3} \mathrm{PO}_{4}, \mathrm{Rb}_{3} \mathrm{PO}_{4}$, and $\mathrm{Cs}_{3} \mathrm{PO}_{4}$ gave lower yields) and various tertiary amines (Entries 4-6). THF was superior to DMSO as the solvent (Entries 2,3 vs. 8,9), while other aprotic and protic solvents were found to be inefficient (MeCN, 1,2-dichloethane, toluene, $\mathrm{MeOH}, \quad 1,1,1,3,3,3-$ hexafluoroisopropanol). An excess of the amine is necessary, and the reaction is best to perform using 2-3 equiv. of the amine (Entry 3 vs. 10 and 11). Screening for the Pd-source indicated that pre-generated $\eta^{3}$-(2-fluorocyclohept-2enyl)palladium complex Pd-cat-II gave superior results (Entry 11), but it is unsuitable for other pyridinium salts. Slightly smaller yields were achieved with $\mathrm{Pd}(\mathrm{OAc})_{2}$ (Entry 13), $\mathrm{Pd}_{2} \mathrm{dba}_{3}$ (Entry 14) and Buchwald's precatalyst Pd-G3 (Entry 15). Though $\mathrm{Pd}(\mathrm{OAc})_{2}$ failed to give the highest yield, it was chosen for further studies on the substrate scope because it adds no extra organic impurity that would have to be separated.

With the optimized conditions at hand, we next tested the scope of amines in this reaction (Scheme 4). Mild reaction conditions allowed us to suggest that selective monoallylation of primary amino groups is possible. Indeed, not only secondary amines (products $\mathbf{4 a - c}$ ), but also primary amines (products $\mathbf{5 a -}$ e) were successfully allylated, with no evidence of side diallylation. The reaction demonstrates good functional group tolerance, and ester (4c), acetal (5c), dialkylamino (5e) groups and furan ring (5d) can be used.
Table 1. Screening of the amination conditions a

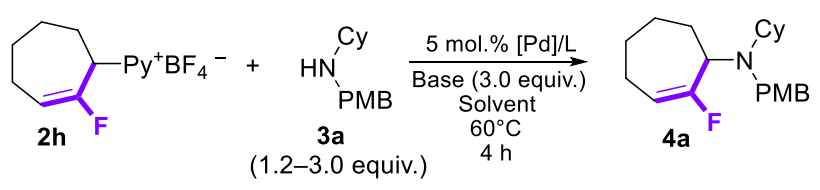

\begin{tabular}{|c|c|c|c|c|c|}
\hline Entry & {$[\mathrm{Pd}] /$ Ligand } & $\begin{array}{c}3 a \\
\text { (equiv.) }\end{array}$ & Base & Solvent & $\begin{array}{l}\text { Yield, } \\
(\%)^{b}\end{array}$ \\
\hline 1 & Pd-cat-I ${ }^{c}$ & 1.2 & $\mathrm{~K}_{3} \mathrm{PO}_{4}$ & THF & 35 \\
\hline 2 & Pd-cat-II ${ }^{c}$ & 1.2 & $\mathrm{~K}_{3} \mathrm{PO}_{4}$ & THF & 40 \\
\hline 3 & Pd-cat-II & 1.2 & $\mathrm{Na}_{3} \mathrm{PO}_{4}$ & THF & 75 \\
\hline 4 & Pd-cat-II & 1.2 & DIPEA & THF & 10 \\
\hline 5 & Pd-cat-II & 1.2 & $\mathrm{Bn}_{3} \mathrm{~N}$ & THF & 20 \\
\hline 6 & Pd-cat-II & 1.2 & $\begin{array}{c}N \text {-Ethyl- } \\
\text { morpholine }\end{array}$ & THF & 20 \\
\hline 7 & Pd-cat-II & 1.2 & - & THF & 30 \\
\hline 8 & Pd-cat-II & 1.2 & $\mathrm{~K}_{3} \mathrm{PO}_{4}$ & DMSO & 60 \\
\hline 9 & Pd-cat-II & 1.2 & $\mathrm{Na}_{3} \mathrm{PO}_{4}$ & DMSO & 60 \\
\hline 10 & Pd-cat-II & 2.0 & $\mathrm{Na}_{3} \mathrm{PO}_{4}$ & THF & 85 \\
\hline 11 & Pd-cat-II & 3.0 & $\mathrm{Na}_{3} \mathrm{PO}_{4}$ & THF & 90 \\
\hline 12 & $\begin{array}{c}\mathrm{PdCl}_{2} / \\
\text { XantPhos }\end{array}$ & 3.0 & $\mathrm{Na}_{3} \mathrm{PO}_{4}$ & THF & 75 \\
\hline 13 & $\begin{array}{l}\mathrm{Pd}(\mathrm{OAc})_{2} / \\
\text { XantPhos }\end{array}$ & 3.0 & $\mathrm{Na}_{3} \mathrm{PO}_{4}$ & THF & 80 \\
\hline 14 & $\begin{array}{c}\mathrm{Pd}(\mathrm{dba})_{1.5} / \\
\text { XantPhos }\end{array}$ & 3.0 & $\mathrm{Na}_{3} \mathrm{PO}_{4}$ & THF & 85 \\
\hline 15 & $\begin{array}{c}\text { Pd-G3/ } \\
\text { XantPhos }\end{array}$ & 3.0 & $\mathrm{Na}_{3} \mathrm{PO}_{4}$ & THF & 80 \\
\hline
\end{tabular}

a Procedure: A mixture of $\mathbf{2} \mathbf{h}(0.10 \mathrm{mmol}), 3 \mathbf{3 a}(0.12-0.30 \mathrm{mmol})$, base (3.0 equiv.), $\mathrm{C}_{19} \mathrm{H}_{40}$ (5-10 mg, internal standard), and $[\mathrm{Pd}] /$ Ligand $(5 \mathrm{~mol} \%)$ in THF $(1.0 \mathrm{~mL})$ was heated at $60^{\circ} \mathrm{C}$ for $4 \mathrm{~h}$ under argon; ${ }^{b}$ Calibrated GC yields are given to the nearest $5 \%$; c The batch solution was freshly prepared from $\eta^{3}$-(2-fluorocyclohept-2enyl)palladium chloride dimer, ${ }^{15} \mathrm{AgOTf}$ (1.0 equiv.), Ligand (2.0 equiv. of $\mathrm{PPh}_{3}$ or 1.0 equiv. of XantPhos) in THF (100 mL/mmol of Pd);
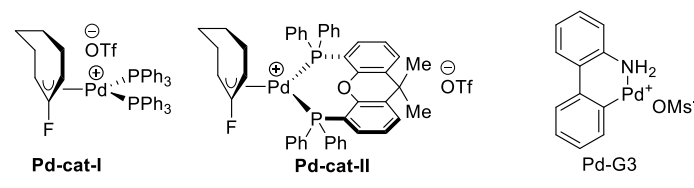

Primary anilines with electron-donating or electronwithdrawing groups can also be successfully allylated to give the corresponding mono-adducts in high to moderate yields (products 6a-e). However, electron-rich anilines are more reactive than electron-poor ones. For example, in the case of the para-nitro group, the target product $6 \mathbf{f}$ was obtained in a low yield, whereas in the case of the ortho-nitro group, only traces of the probable product $\mathbf{6 g}$ were detected by GC. Unfortunately, $\mathrm{N}$-substitution of aniline with a cyclohexyl group makes it completely unreactive, apparently due to steric hindrance (example 6h).

Additionally, $\quad N$-( $p$-methoxyphenyl)tosylsulfamide and phthalimide can also be successfully allylated under these conditions to afford the corresponding products 7 and $\mathbf{8}$ in good yields, whereas $N$-phenylacetamide gives only traces of the probable product $\mathbf{9}$, presumably due to its too low acidity. 


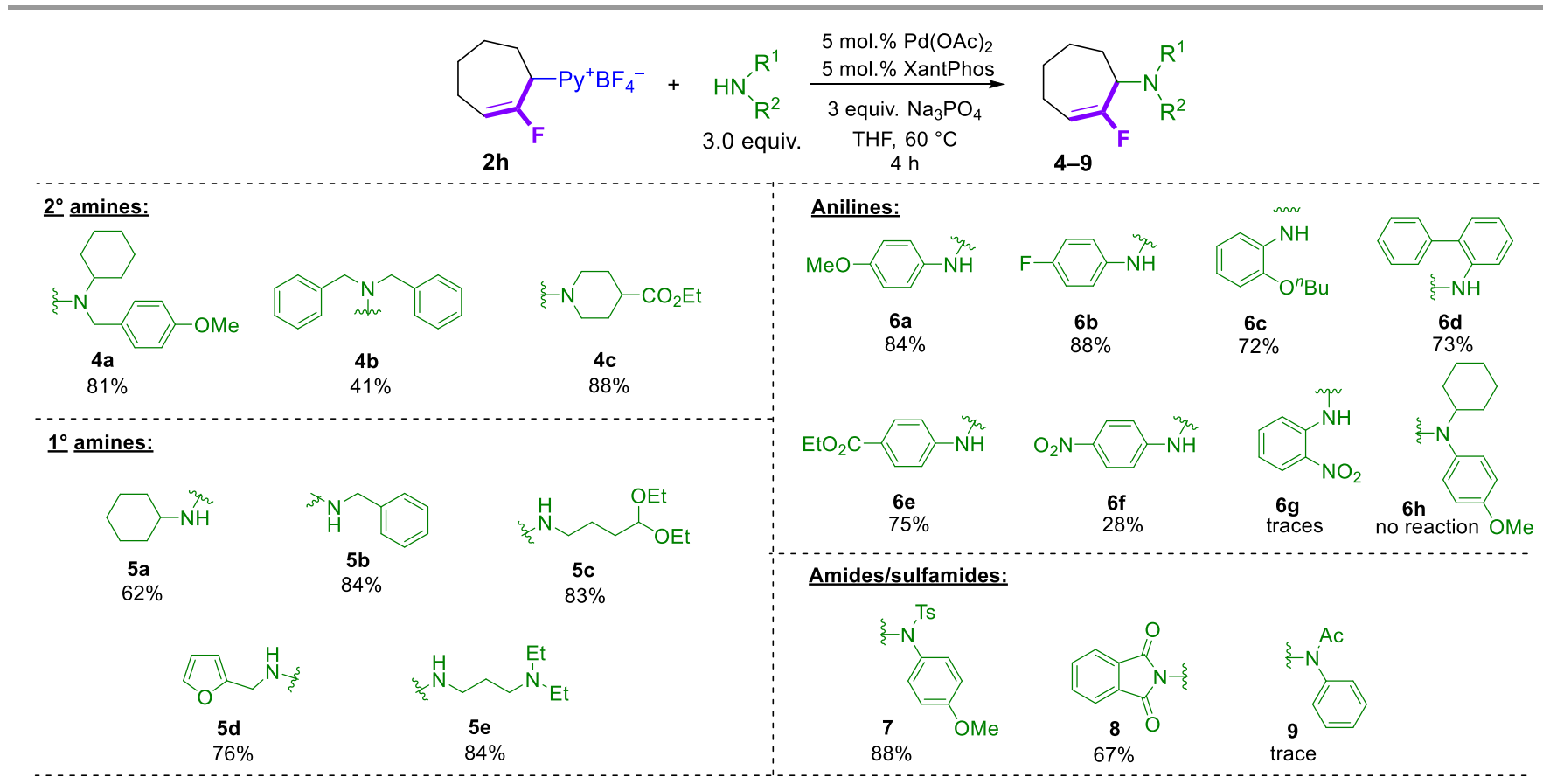

a Procedure: A mixture of $\mathbf{2 h}(1.0 \mathrm{mmol})$, amine/aniline (3.0 mmol), $\mathrm{Na}_{3} \mathrm{PO}_{4}(3.0 \mathrm{mmol}),. \mathrm{C}_{19} \mathrm{H}_{40}(5-10 \mathrm{mg}$, internal standard), and Pd(OAc) $2 / \mathrm{XantPhos}(5 \mathrm{~mol} \%)$ in THF (10 mL) was heated at $60^{\circ} \mathrm{C}$ for $4 \mathrm{~h}$ under argon. The product was isolated by column chromatography;

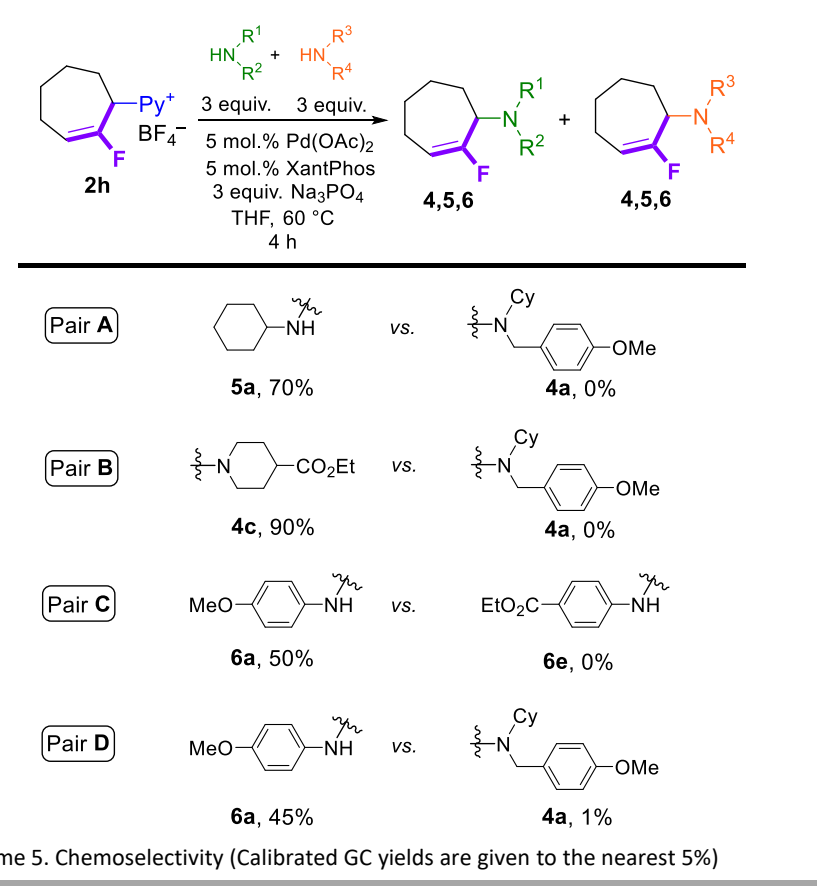

The feasibility of selective allylation of only one amino group in the presence of two or more groups in the target substrate is an important feature of the reaction. To test it, we studied the reaction of pyridinium salt $\mathbf{2} \mathbf{h}$ with pairs of two different amines/anilines (Scheme 5). These experiments again showed that primary amino group could be selectively allylated in the presence of a secondary amino group (pair A). Moreover, piperidine nitrogen can be selectively allylated in the presence of an acyclic secondary amino group (pair B). Electron-rich aniline nitrogen can be selectively allylated in the presence of electron-poor aniline nitrogen (pair C). Interestingly, electronrich aniline nitrogen can be selectively allylated even in the presence of a secondary amino group (pair D). 
Table 2. Pyridinium salt scope $\mathrm{a}^{\mathrm{a}, \mathrm{b}}$
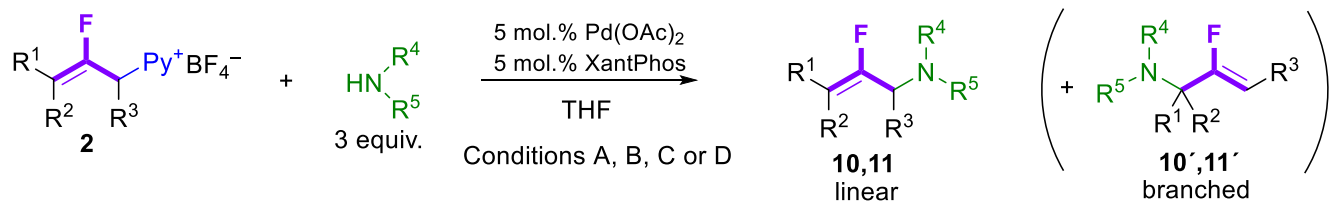

Pyridinium salt

$$
\begin{aligned}
& \text { 10a, } R^{4}=C y, R^{5}=P M B \text { (Conditions A) } \\
& \text { 11a, } R^{4}=P M P, R^{5}=H(\text { Conditions } A) \\
& \text { 10b, } R^{4}=C y, R^{5}=P M B \text { (Conditions } B \text { ) } \\
& \text { 11b, } R^{4}=P M P, R^{5}=H(\text { Conditions } C \text { ) } \\
& \text { 10c, } \mathrm{R}^{4}=\mathrm{Cy}, \mathrm{R}^{5}=\mathrm{PMB} \text { (Conditions } \mathrm{B} \text { ) } \\
& \text { 11c, } R^{4}=P M P, R^{5}=H \text { (Conditions } D \text { ) } \\
& \text { 10d, } R^{4}=C y, R^{5}=P M B(\text { Conditions } B \text { ) }
\end{aligned}
$$$$
\text { Yield, Z/E, linear/branched }
$$$$
83 \%(Z / E=98 / 2)(I / b>20 / 1)
$$$$
73 \%(Z / E=99 / 1)(I / b>20 / 1)
$$$$
78 \%(Z / E>20 / 1)(I / b>20 / 1)
$$$$
59 \%(Z / E>20 / 1)(I / b>20 / 1)
$$

Complex mixture

Complex mixture

$44 \%(Z / E=98 / 2)(I / b>20 / 1)^{c}$

$56 \%(Z / E>20 / 1)(I / b>20 / 1)$

$87 \%(Z / E=91 / 9)(I / b>20 / 1)$

$90 \%(Z / E=81 / 19)^{\mathrm{d}}(I / b=75 / 25)$

$70 \%(Z / E=93 / 7)(I / b>20 / 1)$

$67 \%(Z / E=87 / 13)(I / b>20 / 1)$

$36 \%(E / Z=74 / 26)(I / b>20 / 1)$

Complex mixture

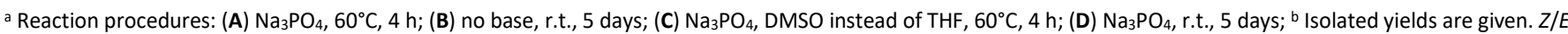
and linear/branched ratios are the same before and after column chromatography, unless otherwise stated; ${ }^{\mathrm{c}}$ Side product $\mathbf{1 2}$ was formed in $13 \%$ isolated yield $(Z / E=$ 96/4); ${ }^{\mathrm{d}} \mathrm{Z} / \mathrm{E}$ ratio of linear isomer; ${ }^{\mathrm{e}}$ Linear/branched ratio before chromatography was of 79/21.

Abbreviations: $\mathrm{PMB}=4$-methoxybenzyl-; $\mathrm{PMP}=4$-methoxyphenyl-.

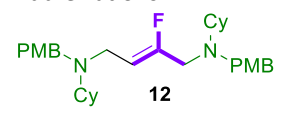

Next, the scope of pyridinium salts was studied using secondary amine $3 a$ or $p$-anisidine as the model nucleophiles (Table 2). In most cases, the corresponding products were obtained in moderate to high yields with excellent $Z / E$ - and linear/branched selectivity. In the case of amine $3 a$, only 2fluorocinnamyl salt $\mathbf{2 a}$ could be aminated under standard conditions (e.g., at $60^{\circ} \mathrm{C}$ at the presence of $\mathrm{Na}_{3} \mathrm{PO}_{4}$ ). In the other cases, room temperature and no additional base were required to get good yields of the products, however, long reaction times were needed (5 days). In this way, the corresponding 2fluoroallyl amines were obtained starting from pyridinium salts containing alkyl substituents (2b, 2f), benzyloxy groups (2d, 2e) or the malonate moiety (2i). Even difluorinated pyridinium salt $2 \mathbf{k}$ could be successfully aminated but gave a low yield of the target product as a mixture of $E / Z$-isomers. Only cyclopropyl substituted salt $\mathbf{2} \mathbf{c}$ failed to afford the target products but gave a complex mixture, presumably due to easy opening of the cyclopropyl group ring in the intermediate allyl palladium complexes.

Notably, pyridinium salts $\mathbf{2 d , e}$ comprise two allylic scaffolds, i.e., 2-fluroallyl pyridinium and 3-fluoroallyl benzoate. The first one, 2-fluroallyl pyridinium, is more reactive in both cases. However, benzoyloxypyridinium salt $\mathbf{2} \mathbf{d}$ gave a distinguishable amount of side diamination product $\mathbf{1 2}$, while this side process was suppressed by the additional methyl group in the case of salt $\mathbf{2 e}$ and only target amine $10 \mathrm{e}$ was obtained. 


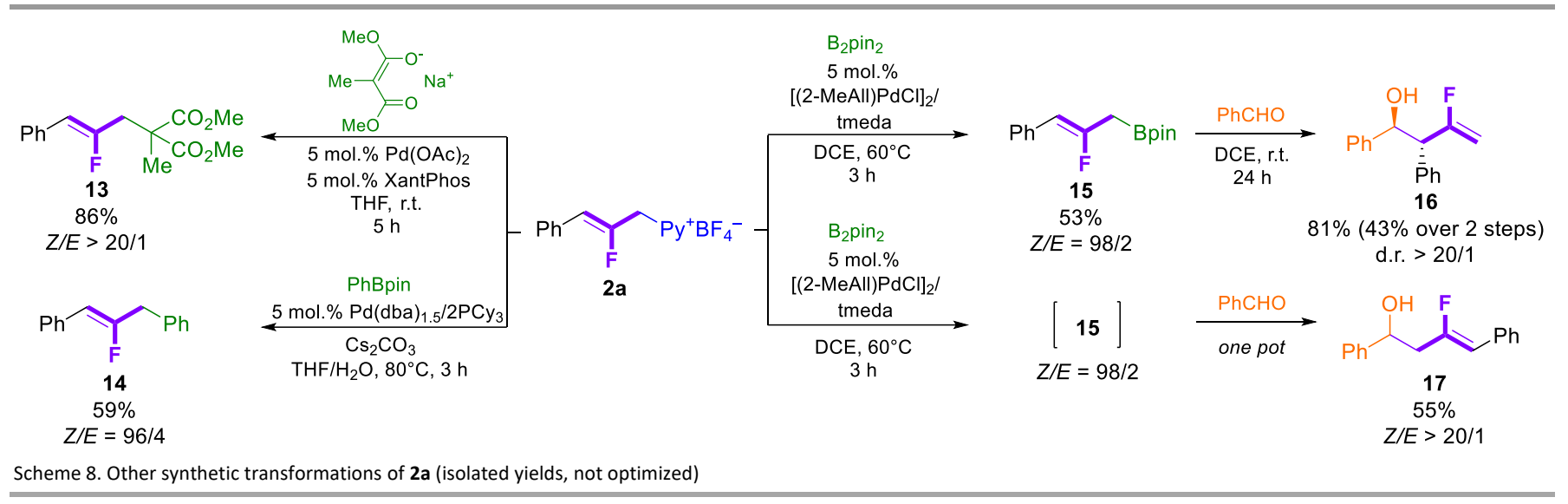

In contrast to amine $3 a, p$-anisidine additionally required $\mathrm{Na}_{3} \mathrm{PO}_{4}$ in all the cases. But again, room temperatures were required for all the salts, except the cinnamyl one (2a). In the case of phenyl methyl salt $\mathbf{2} \mathbf{b}$, changing the solvent to DMSO was required, otherwise substantial formation of a diene side product was noted. In the case of salts $\mathbf{2} \mathbf{h}$ and $\mathbf{2} \mathbf{i}$ where double bonds are not stabilized by conjugation with the aromatic ring, issues with linear/branched selectivity were observed. However, for malonate-containing salt $\mathbf{2} \mathbf{i}$, the side branched isomer could be easily separated off by ordinary column chromatography. Unfortunately, cyclopropyl substituted salt 2c and difluorinated salt $\mathbf{2} \mathbf{k}$ again failed to give the target products.

Not only amines or anilines could be used as nucleophiles in the Pd-catalyzed allylic substitution in 2-fluoroallyl pyridinium salts. 2-Fluorocinnamyl pyridinium salts 2 a reacted with sodium methylmalonate to afford the target $\mathbf{1 3}$ in a high yield and with excellent $Z / E$-selectivity (Scheme 8). Also, Suzuki cross-coupling with phenylboronic acid gave the corresponding product 14 (Scheme 8). However, the yield was not high, likely due to aqueous basic conditions required to activate the boronic ester for the transmetalation step.

Moreover, borylation of $\mathbf{2 a}$ could be successfully done under non-optimized conditions ${ }^{16}$ leading to the corresponding 2fluoroallyl boronate $\mathbf{1 5}$ (Scheme 8), but the yield was only moderate $(53 \%$ vs $88 \%$ in the similar borylation of 2 -fluoro-3phenylallyl chloride ${ }^{16 b}$ ). The isolated boronate $\mathbf{1 5}$ readily reacted with benzaldehyde affording $\mathbf{1 6}$ exclusively as the antiisomer. Unusual results were obtained when boronate $\mathbf{1 5}$ was subjected to the reaction with benzaldehyde without isolation. In this case, linear alcohol $\mathbf{1 7}$ was obtained exclusively as the (Z)-isomer. The origin of such regioselectivity change is still unclear, but probably reversible addition of a 2-fluoroallyl moiety might take place under the latter conditions. ${ }^{16 \mathrm{~b}}$

\section{Conclusions}

In summary, we have disclosed an efficient two-step approach to 2-fluoroallyl amines using (2-fluoroallyl)pyridinium tetrafluoroborates as novel and stable 2-fluoroallyl electrophiles for the Pd-catalyzed allylic substitution. (2Fluoroallyl)pyridinium salts are prepared by $\mathrm{CuBr}$ catalyzed ringopening of readily available gem-bromofluorocyclopropanes in the presence of pyridine. Further Pd-catalyzed amination affords a wide range of 2-fluoroallyl amines and anilines with high regio- and stereoselectivity. The mildness of the reaction conditions allows one to perform the monoallylation of primary amines and anilines selectively, with no evidence of side diallylation. Malonates and arylboronic acids are also suitable nucleophiles for the Pd-catalyzed allylic substitution in 2fluoroallyl pyridinium salts. Moreover, Pd-catalyzed borylation with $\mathrm{B}_{2} \mathrm{pin}_{2}$ gives access to 2-fluoroallyl boronates that can be used for the 2-fluoroallylboration of carbonyl compounds, thus demonstrating that 2-fluoroallyl pyridinium salts are not only valuable electrophiles, but also umpolung of their standard polarity can be easily performed, thus converting them to synthetic equivalents of the 2-fluoroallyl anion.

\section{Conflicts of interest}

There are no conflicts to declare.

\section{Acknowledgements}

This work was funded by Russian Science Foundation (RSF) according to the research project № 19-73-00320. The authors greatly thank Dr. Roman A. Novikov from ZIOC RAS for 1D and 2D NMR assistance.

\section{Notes and references}

1 N. A. Meanwell, J. Med. Chem., 2018, 61, 5822-5880.

2 a) A. Choudhary and R. T. Raines, ChemBioChem, 2011, 12, 1801-1807; b) J. T. Welch, Elsevier B.V., 2008, pp. 699-735.

3 S. D. Edmondson, L. Wei, J. Xu, J. Shang, S. Xu, J. Pang, A. Chaudhary, D. C. Dean, H. He, B. Leiting, K. A. Lyons, R. A. Patel, S. B. Patel, G. Scapin, J. K. Wu, M. G. Beconi, N. A. 
Thornberry and A. E. Weber, Bioorg. Med. Chem. Lett., 2008, 18, 2409-2413.

4 For a review on synthetic approaches to fluoroalkenes, see: a) M. Drouin, J.-D. Hamel and J.-F. Paquin, Synthesis, 2018, 50, 881-955; b) G. Landelle, M. Bergeron, M.-O. Turcotte-Savard and J.-F. Paquin, Chem. Soc. Rev., 2011, 40, 2867-2908; c) H. Yanai and T. Taguchi, Eur. J. Org. Chem., 2011, 2011, 59395954.

5 For a review of fluorocyclopropane ring-opening, see: a) $M$ Fedorynski, Chem. Rev., 2003, 103, 1099-1132; b) W. R. Jr. Dolbier and M. A. Battiste, Chem. Rev., 2003, 103, 1071-1098.

6 For a review on cyclopropyl-to-allyl transformation, see: $\mathrm{H}$. Jendralla, in Methods of Organic Chemistry (Houben-Weyl) (Ed.: A. de Meijere), Thieme, Stuttgart, 1997, vol. E17c, p. 2313.

7 M. Schlosser, Tetrahedron, 1978, 34, 3-17.

8 Recent examples of neighbor group assister ring-opening: a) D. Munemori, K. Narita, T. Nokami and T. Itoh, Org. Lett. 2014, 16, 2638-2641; b) X. Song, C. Xu, D. Du, Z. Zhao, D. Zhu and M. Wang, Org. Lett., 2017, 19, 6542-6545; c) S. Specklin, J. Fenneteau, P. Subramanian and J. Cossy, Chem. Eur. J., 2018, 24, 332-336; c) H. Takenaka, Y. Masuhara, K. Narita, T. Nokami and T. Itoh, Org. Biomol. Chem., 2018, 16, 6106-6114 d) Y. Masuhara, T. Tanaka, H. Takenaka, S. Hayase, T. Nokami and T. Itoh, J. Org. Chem., 2019, 84, 5440-5449; e) X. Liu, D. Du, S. Li, X. Wang, C. Xu and M. Wang, Adv. Synth. Catal., 2020, 362, 5135-5140; f) M. Ramasamy, S. Kuo and M. Hsieh, Eur. J. Org. Chem., 2020, 2020, 5207-5210; g) A. Kazia, R. Melngaile, A. Mishnev and J. Veliks, Org. Biomol. Chem., 2020, 18, 13841388; h) T. Sugiishi, C. Matsumura and H. Amii, Org. Biomol. Chem., 2020, 18, 3459-3462; i) S. Wang, X. Liu, D. Zhu and M. Wang, J. Org. Chem., 2020, 85, 12408-12417.

9 Other methods for ring-opening of non-activated fluorocyclopropanes: a) J. Wenz, C. A. Rettenmeier, H. Wadepohl and L. H. Gade, Chem. Commun., 2016, 52, 202205; b) O. B. Bondarenko, A. A. Vinogradov, A. I. Komarov, G. L. Karetnikov, N. V. Zyk, T. Holt and A. G. Kutateladze, Tetrahedron, 2019, 75, 2861-2865; d) O. B. Bondarenko, A. I. Komarov, G. L. Karetnikov, S. N. Nikolaeva, N. V. Zyk, T. Holt and A. G. Kutateladze, Tetrahedron, 2019, 75, 130666; e) T. Goto, T. Kawasaki-Takasuka and T. Yamazaki, J. Org. Chem. 2019, 84, 9509-9518; d) H. Liu, Y. Li, D.-X. Wang, M.-M. Sun and C. Feng, Org. Lett., 2020, 22, 8681-8686.

10 a) J. Xu, E.-A. Ahmed, B. Xiao, Q.-Q. Lu, Y.-L. Wang, C.-G. Yu and Y. Fu, Angew. Chem. Int. Ed., 2015, 54, 8231-8235; b) E.A. M. A. Ahmed, A. M. Y. Suliman, T.-J. Gong and Y. Fu, Org. Lett., 2019, 21, 5645-5649; c) J. Ni, B. Nishonov, A. Pardaev and A. Zhang, J. Org. Chem., 2019, 84, 13646-13654; d) E.-A M. A. Ahmed, A. M. Y. Suliman, T.-J. Gong and Y. Fu, Org. Lett., 2020, 22, 1414-1419; e) Z. Fu, J. Zhu, S. Guo and A. Lin, Chem. Commun., 2021, 57, 1262-1265.

11 a) T. Nihei, T. Hoshino and T. Konno, Org. Lett., 2014, 16, 4170-4173; b) T. Nihei, T. Hoshino and T. Konno, Org. Biomol. Chem., 2015, 13, 3721-3731.

12 a) M. A. Novikov, N. V. Volchkov, M. B. Lipkind and O. M. Nefedov, Russ. Chem. Bull., 2013, 62, 71-82; b) M. A. Novikov, N. V. Volchkov, M. B. Lipkind and O. M. Nefedov, J. Fluor. Chem., 2015, 180, 131-143; c) M. A. Novikov, Y. A. Ibatov, N. V. Volchkov, M. B. Lipkind, S. E. Semenov and O. M. Nefedov, J. Fluor. Chem., 2017, 194, 58-72.

$13 \mathrm{gem}$-Bromofluorocyclopropanes can be synthesized as following: a) using $\mathrm{CBr}_{2} \mathrm{FCO}_{2} \mathrm{Na}$ under (IPr)AgCl catalysis: A. A Andrianova, Y. D. Maslova, M. A. Novikov, S. E. Semenov and O. M. Nefedov, J. Fluor. Chem., 2018, 209, 49-55; b) using $\mathrm{CHBr}_{2} \mathrm{~F}$ under PTC conditions: for review see ref. ${ }^{2 a}$; c) using $\mathrm{CBr}_{2} \mathrm{FSiMe}_{3}$ : D. Chen, Z. Fan, L. Huang, K. Gao, P. Xiao, C. Ni and J. Hu, Chem. Commun., 2021, 57, 319-322.

14 Synthesis of cyclic fluoroalkenes: a) D. Guérin, I. Dez, A.-C. Gaumont, X. Pannecoucke, S. Couve-Bonnaire, Org. Lett. 2016, 18, 3606-3609; b) Y. He, D. Anand, Z. Sun, L. Zhou, Org.
Lett., 2019, 21, 3769-3773; c) D. Ding, Y. Lan, Z. Lin, C. Wang, Org. Lett., 2019, 21, 2723-2730; d) L. Li, T. Xiao, H. Chen, L. Zhou, Chem. Eur. J., 2017, 23, 2249-2254; e) H. Chen, T. Xiao, L. Li, D. Anand, Y. He, L. Zhou, Adv. Synth. Catal., 2017, 359, 3642-3647; e) E. Block, B. Bechand, S. Gundala, A. Vattekkatte, K. Wang, S. S. Mousa, K. Godugu, M. Yalcin and S. A. Mousa, Molecules, 2017, 22, 2081.

15 A. Yu. Bobrova, M. A. Novikov, I. A. Mezentsev and Y. V. Tomilov, J. Fluor. Chem., 2020, 236, 109553.

16 a) M. A. Novikov and O. M. Nefedov, Org. Biomol. Chem., 2018, 16, 4963-4967; b) M. A. Novikov, A. Yu. Bobrova, I. A. Mezentsev, M. G. Medvedev and Y. V. Tomilov, J. Org. Chem., 2020, 85, 6295-6308. 